INTRODUCCIÓN

\title{
Estado y pueblos indígenas en la Amazonía peruana
}

\section{Danny Pinedo}

https://orcid.org/0000-0003-0594-4986

Universidad Nacional Mayor de San Marcos

dpinedog@unmsm.edu.pe

La antropología ha caracterizado a los pueblos indígenas de la Amazonía como sociedades sin Estado. El antropólogo francés Pierre Clastres llegó incluso a sostener que los indígenas sudamericanos que él estudió no solo carecían de organización estatal, sino que se esforzaban por evitar la formación de un poder centralizado independiente de la sociedad (Clastres, 1974). Asimismo, se ha argumentado que luego de la conquista europea del Nuevo Mundo, los indígenas amazónicos, a diferencia de las sociedades andina y mesoamericana, permanecieron en los márgenes del Estado hasta épocas recientes. A pesar de ello, los indígenas amazónicos no han permanecido fuera de la influencia del Estado, habiendo tenido más bien una larga historia de interacción con diferentes formas de Estado, desde el Estado inca hasta el Estado republicano.

La respuesta de los pueblos indígenas a la formación del Estado no siempre ha sido la resistencia. En varios momentos históricos, los indígenas amazónicos han aprovechado contextos políticos favorables para promover sus intereses dentro de los límites de las políticas estatales. A veces, las estrategias políticas de los pueblos indígenas resultaron en nuevas legislaciones o afectaron las políticas estatales. En este proceso, antes que receptores pasivos de las políticas estatales, los indígenas amazónicos han jugado un papel central en los procesos de formación del Estado en la Amazonía (Clark y Becker, 2007).

Pero, así como la respuesta de los pueblos indígenas a las políticas del Estado no ha sido siempre la de la resistencia, la acción del Estado no se ha caracterizado necesariamente por la expansión depredadora sobre los territorios indígenas. Esta visión del Estado tiene que ver principalmente con la manera en que entendemos 
eso que llamamos Estado. Una visión del Estado muy arraigada, y de la cual los antropólogos no han estado exentos, es la que lo caracteriza como un fenómeno dado y estático, caracterizado por un aparato centralizado, unitario y con contornos claramente definidos y al margen de la sociedad (Abrams, 2015; Mitchell, 2015).

Sin embargo, el Estado no debe ser visto ahistóricamente ni como una entidad natural. El Estado ha tenido diferentes trayectorias históricas y presenta características distintas. Por eso, no ha sido el mismo a lo largo del tiempo ni es igual en todos lados. Tampoco es un actor social monolítico sino uno que está atravesado por ambiguedades y contradicciones. Es justamente esta caracterísitica la que ha hecho posible que, en circunstancias históricas particulares, los pueblos indígenas hayan sacado ventaja de las contradicciones internas del Estado para impulsar reformas en él, que además han tenido como vías los mismos instrumentos legales del Estado. Además, el Estado no debe ser reducido a un conjunto de aparatos administrativos, sino que es también ideología y representación (Corrigan y Sayer, 1985). Por lo tanto, debe ser entendido como una configuración históricamente específica tanto de prácticas como de ideas.

\section{EL EsTado inca}

A pesar de su política expansionista, los incas fracasaron en su intento de conquistar militarmente a los pueblos indígenas de la frontera oriental de su imperio. Los incas solo pudieron incorporar algunos pueblos amazónicos, como es el caso de pueblos del alto Marañón y en cierta medida los de la región entre el Marańón y el bajo Huallaga (Taylor, 1999). En estas regiones, los incas instalaron mitimaes y deportaron a parte de la población indígena, impusieron tributos, entablaron relaciones de alianza y de afinidad con los líderes locales, y explotaron los recursos naturales. En la mayoría de los casos, sin embargo, los incas buscaron relacionarse con los indígenas amazónicos mediante el intercambio de dones, insertándose en las redes locales de comercio intertribal. Por su parte, los indígenas amazónicos enviaban a la frontera pequeños grupos de colonos para mediar las relaciones de intercambio y alianza con los incas. También manipulaban estos intercambios, forzando a los incas a devolver los regalos con más frecuencia. En este contexto, el vasallaje de los pueblos amazónicos era más nominal que real. Se ha afirmado también que las expediciones militares contra los pueblos de la selva no eran una manifestación de expansionismo, sino más bien formas de antagonismo ritual que expresaban el esquema dualista andino (Taylor, 1999). En la mitología e iconografía inca, la Amazonía constituía un elemeno complementario en un orden jerárquico que postulaba la oposición entre una mitad andina masculina y superior y otra mitad amazónica salvaje y amenazante. 
En este contexto, la frontera era poco definida y bastante abierta. Así, las relaciones entre los pueblos amazónicos y los incas fueron en realidad mucho más flexibles, ambiguas e inestables de lo que los cronistas han descrito. Estas relaciones pueden describirse más bien como situaciones intermedias entre la completa incorporación y la hostilidad permanente, y es claro que antes que ser impuestas, eran con frecuencia negociadas, a veces a favor de los amazónicos. Finalmente, la ideología inca relegó a las poblaciones de la selva a un estatus de inferioridad antagónica, una polarización que redefinió las identidades tribales. La política inca condicionó de esta manera los procesos de transculturación y de cambios en la identidad que caracterizaron a las sociedades amazónicas desde la seguna mitad del siglo XVI. A pesar que durante el período inca los pueblos andinos y amazónicos permanecieron física, económica y sociológicamente muy cercanos, surgió gradualmente una frontera conceptual, política y cultural entre ambas sociedades.

\section{El Estado colonial}

El periodo colonial estuvo marcado por un débil control estatal. En esta época, la Amazonía fue vista como una fuente de recursos naturales y de mano de obra indígena. Sin embargo, la penetración española tuvo marcadas diferencias entre la Amazonía norte y sur (Taylor, 1999). En la Amazonía sur, la mayoría de entradas al oriente tuvo resultados desastrosos y no produjo asentamientos coloniales duraderos. La frontera que emergió fue mucho más superficial que la del imperio inca. Con el propósito de forzar a los españoles a entrar en relaciones comerciales y a través de ellas obtener herramientas de metal, los indígenas amazónicos toleraron el levantamiento de asentamientos españoles en la frontera, tal como habían hecho con los incas. Pero tan pronto como los españoles trataron de esclavizarlos o empujarlos hacia el interior, los pueblos amazónicos unieron fuerzas para expulsarlos, con lo cual el comercio en la frontera se tornó en pillaje. Así, a lo largo de los siglos XVI y XVII los indígenas amazónicos mantuvieron tanto la montańa central del Perú como el piedemonte boliviano cerrados a la penetración española, permitiendo solo el ingreso de expediciones comerciales de pequeńa escala y, más tarde, de pequeños grupos de misioneros.

La situación en la selva norte fue diferente. Aquí los españoles realizaron entradas consecutivas al valle del Marañón y al área entre el Marañón y el bajo Huallaga. Los capitanes que comandaron varias de estas entradas distribuyeron cientos de encomiendas mediante las cuales los espańoles ejercieron un alto grado de control y explotación sobre la población nativa. Sin embargo, este proceso no fue acompañado de control estatal. Los colonos frecuentemente desobedecían a las autoridades de la corona o se rebelaban contra ellas, dedicándose al saqueo, la esclavitud o la exploración de oro en zonas muy distantes de sus asentamientos, a pesar de que la corona había prohibido la esclavitud (Werlich, 1968). A diferencia 
de la sierra, donde la encomienda era principalmente un medio para extraer tributo de poblaciones indígenas sedentarizadas y bien controladas, en la selva la encomienda sirvió como un marco legal para reclutar y controlar mano de obra indígena, la cual era utilizada principalmente en la recolección de productos y la prestación de servicios domésticos. La baja producción, los altos costos de transporte y los bajos precios de los productos amazónicos no justificaban la imposición de tributos en la selva. Si bien esta economía de esclavos generó muy poca riqueza, sus efectos sobre los indígenas fueron devastadores. La mayoría de indígenas cautivos huía o moría debido a las epidemias, el maltrato y la desesperación. Desde 1580, la mayoría de españoles regresó a la sierra o abandonó sus encomiendas. Las poblaciones serranas que actuaban como nexos entre la sierra y la selva regresaron a sus lugares de origen o buscaron refugio en las zonas más orientales de la selva. Los indígenas, por su parte, organizaron levantamientos, recuperaron el control de algunos pasajes claves entre la sierra y la selva, particularmente en territorio jíbaro, o abandonaron las laderas y valles orientales más cercanos a los pueblos andinos. Esto ensanchó el vacío entre la sierra y la selva, lo que exacerbó la división espacial, social, económica, cultural y étnica entre los pueblos de la sierra y la selva que ya había empezado en el período inca.

En este contexto, surgió una frontera que separaba las áreas sujetas al poder central español de aquellas nominalmente poseidas pero no controladas, y separaba el territorio de las poblaciones civilizadas de las de salvajes infieles. Así, la única forma de afirmar la presencia de la corona en la frontera fue delegar el manejo de los avances del imperio a las órdenes religiosas. En efecto, el rol de las misiones fue allanar el camino para la expansión de las instituciones coloniales a través del adoctrinamiento de los indígenas en las virtudes del trabajo. Misioneros y colonos dependían entre sí para su propia sobrevivencia. Los colonos alentaron la presencia de los misioneros con la esperanza de que los ayudaran a controlar y estabilizar a la peligrosamente rebelde población indígena. A su vez, las encomiendas proveían a las reducciones de una clientela permanente de indígenas que huían de las exacciones de los encomenderos o los esclavistas. El establecimiento de las misiones coincidió con la ruptura de los circuitos comerciales y de alianza que unían los pueblos de la sierra y la selva. Por ello, permitir el ingreso de los misioneros fue visto por los indígenas como la forma menos onerosa de obtener bienes de origen occidental o serrano. Pero las misiones carecían de una infraestructura administrativa y militar organizada para consolidar su control sobre los indígenas, quienes se rebelaban o huían tan pronto como el flujo de herramientas de metal cesaba.

A lo largo de la era colonial, jesuitas y franciscanos compartieron la evangelización y administración de la selva, excluyendo otras órdenes religiosas. Las reducciones jesuitas no eran asimilasionistas, sino que promovían la idea 
de una república de indios completamente autónoma, nominalmente sujeta al poder de la corona, pero en la práctica independientes de la administración local (Marzal, 1984). Los jesuitas buscaron explícitamente preservar la diferencia indígena y generar una cultura nativa sincrética, para lo cual impusieron el uso del quechua en el alto Marañón y extendieron el uso del mojo arawak como lengua indigena standard en los llanos del norte. Las reducciones jesuitas también sirvieron como amortiguamiento contra la expansión portuguesa (Werlich, 1968). Ideológicamente, los franciscanos fueron abiertamente integracionistas, cuyo ideal era la de la comunidad de aldea agraria, con lo cual se buscaba recrear campesinos cristianos.

En el último cuarto del siglo XVIII, la corona española renovó su interés en el desarrollo económico de la selva peruana a través de proyectos como la construcción de caminos, la colonización, así como la protección policial, la provisión de tierra y herramientas y la exoneración de impuestos a los colonos (Hill, 1999). La montańa peruana empezó entonces a ser percibida como una despensa de productos agrícolas y forestales para pueblos mineros de la sierra que no eran capaces de mantener a sus propias poblaciones. El gobierno colonial envió tropas para contener las incursiones de portugueses contra los misioneros y colonos a lo largo de los ríos Ucayali, Marañón y Napo. Hacia 1780, epidemias de gripe, viruela, sarampión y otras enfermedades contagiosas llevaron a una mayor despoblación. Solo el colapso del gobierno colonial al final del siglo XVIII salvó a los pueblos indígenas de un aniquilamiento total al darles algunas décadas para recuperarse de sus pérdidas en relativa paz. Las guerras de independencia y el periodo subsiguiente de inestabilidad en los nuevos Estados independientes mantuvieron este periodo de recuperación hasta la mitad del siglo XIX.

La dominación colonial tuvo profundos efectos sobre la territorialidad, el hábitat y la cultura de los pueblos indígenas de la alta Amazonía. Primero, algunos pueblos indígenas optaron por el absoluto aislamiento y la independencia del control colonial. Segundo, el aislamiento, los desplazamientos forzosos y la transculturación individual y colectiva llevó a la disolución o transformación étnica y cultural de algunos grupos dialectales. La búsqueda de protección en las misiones llevó a muchos grupos a adoptar un dialecto, identidad y estilo de vida foráneos, desarrollándose identidades borrosas y cambiantes basadas en la incorporación en una cultura sincrética. Las formas sociales más originales que evolucionaron en las reducciones o alrededor de asentamientos españoles o zonas de refugio fueron las "tribus" coloniales. Por otro lado, muchos pueblos indígenas adoptaron un patrón de hábitat disperso y de unidades domésticas aisladas. Esta atomización residencial y social a su vez llevó a los grupos locales a una creciente autonomía y movilidad (Taylor, 1999). 


\section{El Estado REPUblicano}

A finales del periodo colonial, las elites políticas criollas volcaron toda su atención a las reformas borbónicas y a las guerras de independencia, perdiendo interés en los marginales y poco productivos bosques amazónicos (Taylor, 1999). Más tarde, cuando las guerras de independencia llegaron a su fin, empezó un periodo de crisis económica e inestabilidad política que duró hasta mediados del siglo XIX. Como consecuencia, a inicios del siglo XIX el frente de colonización se contrajo y la misionización retrocedió o se detuvo. La reducción del gobierno y de la autoridad eclesiástica en la selva ofreció a los indígenas un periodo de relativa autonomía y de recuperación de los colapsos demográficos producidos por epidemias, guerras y comercio de esclavos durante el periodo colonial (Hill, 1999). En algunas áreas, los indígenas recuperaron los territorios de las cuencas bajas que habían perdido durante esta época.

A mediados del siglo XIX, la deuda externa contraida durante las guerras de independencia y la amenaza de la bancarrota impulsó a los nuevos Estados independientes a reconquistar la frontera amazónica y transformarla en fuente de tierras, alimentos y materias primas para la exportación (Hill, 1999). Se retomó entonces la colonización de la Amazonía, lo que significó un retorno a las políticas económicas de finales de la época colonial, que veían a la región amazónica como una despensa para las poblaciones de la sierra y la costa. El Estado peruano mejoró las comunicaciones con la selva e incrementó la presencia militar, administrativa y política en esta región (Taylor, 1999). Se incrementó la actividad comercial entre la sierra y la selva, se promovió el crecimiento de ciudades, se alentó la expansión de la frontera agrícola y se intensificó la explotación de recursos forestales, sobre todo del caucho a raíz del aumento de la demanda mundial de este producto. El ejército, los patrones del caucho y finalmente inmigrantes asediaron la selva en forma masiva y cada vez con más violencia (Santos Granero y Barclay, 2002).

En esta época, los nuevos Estados-nación sudamericanos ejercían una débil soberanía sobre sus territorios amazónicos. Para demostrar su presencia política en estos territorios, las nuevas repúblicas promovieron la explotación del caucho y otros recursos naturales, lo cual les proveería además parte de las ganancias que se obtendrían de la exportación de la goma silvestre (Brown y Fernández, 2001). Así, cedieron el control de grandes extensiones de bosque a corporaciones europeas a cambio de rebajar la deuda externa, apoyando así a poderosos intereses económicos que habían asumido la conquista de la selva. La competencia por el control de estos territorios provocó disputas limítrofes en las que los indígenas a menudo se encontraron atrapados (Hill, 1999). Para proteger a los colonos del ataque de los indígenas, el gobierno peruano organizó campańas militares y nuevos proyectos de desarrollo agrícola. También, como en el caso de Ecuador, el Estado nombró a misioneros jesuitas como representantes del gobierno. El 
poder que de esta manera ganaron los jesuitas les permitió nombrar funcionarios, abrir escuelas, restringir el comercio y aplicar sanciones legales y castigos a los habitantes de la región (Reeve, 1988).

El incremento de la colonización y la extracción de recursos naturales en la Amazonía tuvo efectos devastadores en la población indígena. Los indígenas no solo se vieron forzados a abandonar las riberas de los ríos y a desplazarse hacia áreas remotas e inaccesibles, perdiendo así el control de parte de sus territorios, sino también perdieron la mayor parte de su población $\left(\right.$ Hill, 1999) ${ }^{1}$. Las grandes redes de comercio interregional se rompieron gradualmente, aislando a los pueblos, tribus y comunidades que en edelante tuvieron que enfrentar individualmente el asedio de patrones del caucho, colonos y militares. Así, la relativa autonomía de los indígenas se transformó en esclavitud, reasentamiento forzoso e incluso genocidio. Los intereses nacionales en establecer presencia política en la frontera amazónica y extraer beneficios económicos para pagar las deudas con los acreedores extranjeros, así como las ideologías extremistas de progreso material a cualquier precio, empujaron a las naciones a evadir la responsabilidad de proteger a los indígenas de los actos de agresión y esclavitud de parte de caucheros y colonos.

El concepto de Estado-nación liberal bajo el cual se crearon las nuevas repúblicas latinoamericanas del siglo XIX puso a los pueblos indígenas amazónicos en una situación social contradictoria. Por un lado, el Estado liberal prometía igualdad civil y legal a todos los ciudadanos dentro de sus fronteras. Por otro lado, debido a la naturaleza racionalista, asimilasionista e individualista de esta igualdad, los pueblos indígenas fueron vistos como iguales solo en la medida en que renunciaran a sus culturas e identidades indígenas (Urban y Sherzer, 1991). Las fuerzas políticas y económicas de las nuevas repúblicas abrazaron ideologías de progreso que definían a los pueblos indígenas como grupos marginales, atrasados y cuya existencia amenazaba el orden social y el progreso (Hill, 1999). Estas ideologías rebajaban a los indígenas a la condición de subhumanos, cuyo único destino era la asimilación, el reasentamiento o la aniquilación. Si los indígenas rechazaban el nuevo orden de la sociedad, eran categorizados como salvajes. La idea de igualdad política vino de la mano, pues, de una retórica nacionalista que enmascaraba creencias coloniales sobre la inferioridad racial y cultural de los indígenas, de modo que el legado colonial de una jerarquía social rígida persistió a pesar de la retórica oficial de igualdad en las nuevas repúblicas.

\footnotetext{
${ }^{1}$ Sin embargo, los pueblos indígenas de las zonas interfluviales no fueron mayormente afectados. En la Amazonía sur, por ejemplo, los indígenas ocupaban ambientes poco propicios para la agricultura de plantación o la ganadería, y por lo tanto permanecieron fuera de las esferas de influencia política y económica de las emergentes naciones. En este contexto, algunos pueblos indígenas incrementaron sus números y desarrollaron etnicidades tribales fuertemente explícitas (Hill, 1999).
} 
En las últimas décadas del siglo XIX, esta situación empezó a cambiar como resultado de movilizaciones indígenas en la sierra y del desarrollo del movimiento indigenista. Esto provocó que, durante el gobierno de Augusto B. Leguía (19191930), se crearan algunos organismos para la atención de problemas vinculados con los pueblos indígenas, y se reconociera la existencia legal de las comunidades indígenas en la Constitución de 1922. Sin embargo, estas políticas indigenistas continuaron el proyecto asimilasionista que había caracterizado al Estado desde los inicios de la República. Así, las instituciones tutelares de los pueblos indígenas estaban dirigidas a lograr su integración a la sociedad nacional. Estas reivindicaciones indigenistas, sin embargo, alcanzaron solo a los indígenas andinos y a pueblos antiguos de la costa. Los pueblos indígenas de la Amazonía continuaron siendo tratados como tribus salvajes que no tenían posibilidad de acceder a derechos ciudadanos como la propiedad de la tierra, mereciendo en el mejor de los casos una protección paternalista por parte del Estado. De ahí que cuando se les reconoció algunos derechos, estos eran prerrogativas que debían quedar sin efecto una vez que fueran asimilados a la nación (Chirif y García Hierro, 2007).

A inicios de la década del setenta, el gobierno militar de Juan Velasco Alvarado impulsó la asimilación de los indígenas andinos a través de su conversión en campesinos y ciudadanos. Velasco promovió el reconocimiento y revalorización de los idiomas indígenas, especialmente del quechua, incluyendo su incorporación en el sistema educativo. Asimismo, cambió el estatus legal de las llamadas comunidades indigenas, las cuales pasaron a llamarse comunidades campesinas. Esta conversión a la ciudadanía suponía, sin embargo, el abandono de su condición de indígenas. El Estado buscó organizar a los indígenas en organizaciones modernas y estructuradas de acuerdo con las leyes del Estado y no de formas de organización tradicional (Bengoa, 1995). Estos cambios se hicieron en el marco de un proyecto de modernización del país que incluyó la Reforma Agraria de 1969, la cual aniquiló la clase terrateniente tradicional. Para la Amazonía, el gobierno de Velasco promulgó en 1974 el Decreto Ley 20653 (Ley de Comunidades Nativas), que reconoció a los asentamientos indígenas como comunidades nativas y les confirió, por primera vez en la historia republicana del Perú, derechos legales a la propiedad de la tierra. La comunidad nativa se convirtió así en el primer sujeto de derecho indígena en la Amazonía, con lo cual los indígenas amazónicos pudieron obtener derechos sobre sus tierras dentro del marco jurídico peruano.

Concluida la etapa de reformas agrarias a mediados de la década del setenta, surgió en América Latina un periodo postindigenista que se ha caracterizado por el surgimiento de nuevos movimientos indígenas que hacen frente ante la amenaza de los procesos modernizadores sobre las sociedades indígenas. Bajo la influencia de la Declaración de Barbados, el Convenio 169 de la Organización 
Internacional del Trabajo y la Declaración de las Naciones Unidas sobre los Derechos de los Pueblos Indígenas, los pueblos indígenas empezaron a criticar duramente las posturas integracionistas del indigenismo estatal, reivindicando su derecho a la autonomía cultural, política y territorial. Si bien la Constitución de 1993 adoptó varios de los elementos del multiculturalismo -como el reconocimiento de la pluralidad cultural del país y la obligación del Estado de proteger la identidad cultural, la autonomía y la propiedad colectiva de las comunidades campesinas y nativas- en la práctica esto no ha pasado de ser un elemento retórico.

\section{RELACIONES ENTRE EsTADO Y PUEBLOS INDÍGENAS HOY}

Este dossier de la Revista de Antropología reúne un conjunto de artículos escritos por antropólogos que proponen diversas miradas sobre las relaciones entre el Estado y los indígenas amazónicos. Los artículos muestran tanto las dimensiones materiales y simbólicas de esta interacción, así como los diversos escenarios en que tiene lugar, los cuales incluyen la expansión de las industrias extractivas, los conflictos sociales, la creación de áreas naturales protegidas y la protección de los pueblos indígenas en aislamiento y contacto inicial. Coincidentemente, cuatro de los artículos presentados en este volumen tienen como estudios de caso a pueblos indígenas que habitan en lo que hoy es el departamento de Madre de Dios, una región que hasta finales del siglo XIX no se encontraba plenamente integrada al territorio nacional peruano. La débil presencia de las instituciones estatales en esta región se ha visto reflejada en la existencia de regiones de refugio para pueblos indígenas que, escapando de las atrocidades cometidas por los barones del caucho a inicios del siglo XX, decidieron permanecer al margen del Estado. Sin embargo, como varios de los artículos así lo muestran, si bien estos pueblos indígenas han limitado sus relaciones directas con la sociedad nacional, no están exentos de los impactos, mayormente negativos, que esta sociedad ejerce sobre ellos.

Moore hace un análisis de los conceptos y las prácticas políticas entre los arakbut de la Amazonía sur del Perú, desde sus primeros contactos permanentes con la sociedad nacional, en la década de 1950, hasta la actualidad. A partir de material etnogáfico recogido a través de su trabajo de campo con ancianos que vivieron en tiempos previos al contacto, y de sus observaciones a través de los años, Moore sostiene que los arakbut poseen un sistema político que combina prácticas tradicionales con organizaciones que han adoptado a través de su interacción con el Estado peruano. Para Moore, el sistema político tradicional de los arakbut corrobora el modelo planteado por Pierre Clastres, en el sentido de que se caracteriza por la igualdad social, el predominio de las relaciones de parentesco, y la presencia de líderes cuya influencia no se basa en el poder coercitivo sino en el prestigio que se obtiene a través de la generosidad en la distribución de bienes. 
Si bien Moore reconoce que el modelo de Clastres es un ideal y que por lo tanto no se aplica a pueblos socialmente complejos y con una estratificación social incipiente, sí es válido para pueblos amazónicos como los arakbut que estuvieron fuera de la influencia de las principales redes de intercambio. Moore concluye que si bien los arakbut han adoptado nuevas formas de organización y práctica política-como las autoridades comunales, la federación nativa y la participación en comicios electorales para los gobiernos locales y regionales- ello no significa que hayan abandonado sus formas tradicionales de organización política. Las prácticas tradicionales se aplican a los asuntos internos a la comunidad, mientras que las relaciones con el Estado son el campo de una combinación de formas políticas tradicionales y modernas.

El artículo de García examina una de las formas más importantes a través de las cuales los indígenas amazónicos han interactuado con el Estado: las áreas naturales protegidas creadas sobre territorios indígenas. A partir del caso de los matsigenka y de pueblos indígenas en aislamiento que habitan al interior del Parque Nacional del Manu, García analiza las tensiones generadas por la superposición de una área protegida sobre territorios indígenas ancestrales. Gran parte de estas tensiones se produjeron por las políticas aplicadas por el Estado, según las cuales se permitía la presencia de los indígenas dentro del parque a condición de que mantuvieran un estilo de vida tradicional. En la base de los proyectos estatales de creación de parques nacionales está la división entre naturaleza y sociedad, así como la concepción de que la sociedad es una amenaza para la naturaleza. De ahí que el primer plan maestro del Parque Nacional del Manu haya previsto el desplazamiento de los pueblos indígenas fuera de él una vez que se hayan modernizado. El artículo muestra cómo el Estado construye categorías como cultura tradicional y cultura moderna, asociando lo tradicional a los pueblos indígenas y asumiendo esta categoría como única condición para su permanencia en el parque. Por lo tanto, los procesos de modernización y aculturación son causales de la reubicación de los pueblos indígenas. El predominio de una ideología proteccionista en la gestión de las áreas protegidas ha llevado al Estado peruano a no respetar los derechos de los pueblos indígenas que habitan al interior de ellas. Esto se ha visto reflejado en la resistencia por parte del Estado a formar equipos permanentes de antropólogos y a normar, financiar o implementar planes antropológicos para el Parque Nacional del Manu.

Torres, Opas y Shepard, Jr. hacen un análisis comparativo de las políticas públicas sobre pueblos indígenas en aislamiento en Perú y Brasil. Los autores sostienen que en estos dos países dos grandes paradigmas han dominado las políticas nacionales sobre pueblos indígenas en la Amazonía: el paradigma asimilacionista y el paradigma de la autonomía. Ambos paradigmas han afectado de manera diferencial las políticas públicas para pueblos indígenas en situación 
de aislamiento y contacto inicial, tanto en el pasado como en la actualidad. A partir de la década de los ochenta, los gobiernos establecieron políticas de no contacto, que evitaban intervenciones directas en estos pueblos, reconociendo así su derecho a la autodeterminación. Sin embargo, en la actualidad se considera un riesgo latente el retroceso hacia políticas de asimilación, especialmente en Brasil. A partir del caso de los mashco piro del río Alto Madre de Dios, los autores enfatizan cómo el contexto de crecientes amenazas externas sobre el territorio de este pueblo hacen compleja la implementación de las políticas de no contacto. Los mashco piro han establecido desde hace décadas interacciones con población local, misioneros y turistas. La atracción desde fuera que generaron los elementos externos (herramientas, alimentos cultivados, sogas y prendas de vestir) que estas interacciones pusieron al alcance de los mashco piro hizo que desde el 2015 este pueblo empezara a establecer un relacionamiento directo, recurrente y sostenido con agentes estatales. En este contexto, no era posible aplicar una política irrestricta del no contacto. Por ello, en julio del 2015 el Ministerio de Cultura aprobó el Plan de Atención Especial para formalizar el relacionamiento directo entre funcionarios y los mashco piro. Según los autores, este plan no tenía como objetivo atraer a los mashco piro a la vida sedentaria, sino más bien mantenerlos alejados de las comunidades nativas y evitar confrontaciones. El artículo concluye que si bien las intervenciones adecuadas son útiles en situaciones de emergencia, no se puede descartar la posibilidad de que lleven a un desastre demográfico. Por eso, las políticas se orientan a evitar el contacto a menos que sea absolutamente necesario.

En su artículo, Huertas analiza cómo, en el contexto de una mayor interacción de pueblos indígenas en aislamiento con poblaciones vecinas en Perú y Brasil, algunos investigadores, principalmente antropólogos, han impulsado el retorno a políticas de contacto controlado o contacto forzado, que suponen un relacionamiento directo y permanente entre el Estado y los indígenas en aislamiento. El artítulo sostiene que esta postura no solo vulnera el derecho de estos pueblos a la autodeterminación, ignorando con ello su decisión de evitar la interacción con la sociedad mayor, sino que no toma en cuenta los riesgos y efectos devastadores que dicha postura ha tenido históricamente sobre la integridad física, sociocultural y territorial de los indígenas. Para Huertas, el contacto controlado implica la sedentarización y la nucleación de los indígenas, lo cual favorecería el contagio de enfermedades, la disminución de fuentes de alimento y la contaminación del espacio. Esta postura ha flexibilizado los principios y estándares de la protección de estos pueblos, los cuales son resultado de las luchas de organizaciones indígenas y activistas y hoy están codificados en la ley e instrumentos internacionales. Además, esta flexibilización facorece la apertura de los territorios de estos pueblos a los proyectos de inversión que el Estado prioriza. El artículo propone que el planteamiento del contacto controlado sobrevalora la capacidad del Estado para manejar satisfactoriamente 
la interacción y sus situaciones de riesgo, así como para controlar el acceso a los territorios indígenas. Sin embargo, estas limitaciones no justifican la ejecución del contacto controlado, sino más bien el fortalecimiento de los mecanismos de control territorial. En contraposición a este planteamiento, la autora propone que el Estado y los antropólogos deben respetar las decisiones de los pueblos en aislamiento sobre su forma de vida y el nivel de relacionamiento con la sociedad más amplia. Este derecho implica también que si estos pueblos deciden incrementar sus interacciones, el Estado debe garantizar un periodo de adaptación para asegurar su integridad física, sociocultural y territorial.

Finalmente, el artículo de Larsen plantea que los eslóganes que han acompañado los procesos de reforma neoliberal en el Perú fueron claves para generar las contradicciones que han azuzado conflictos sociales y ambientales en la Amazonía peruana. Tomando como estudio de caso los eventos violentos del Baguazo del 2009, Larsen cuestiona las visiones que relegan a los eslóganes a meras cuestiones de forma, planteando en su lugar verlos como vehículos poderosos de simplificación y polarización que son necesarios para la afirmación de la superioridad moral del proyecto neoliberal. El eslogan del perro del hortelano, aparecido en varios artículos escritos por el expresidente Alan García, contenía retóricas persuasivas que ofrecían soluciones simples a problemas que supuestamente no habían podido ser resueltos por la burocracia estatal. Estas narrativas se convirtieron en un guión de legitimidad para un paquete de decretos legislativos que promovía la reducción de la intervención estatal en la economía, una política que vulneraba los derechos colectivos y la base de recursos de los indígenas amazónicos. Los eslóganes usaron imágenes estereotipadas que alimentaron la polarización necesaria para construir la legitimidad de la política autoritaria como "buena conducta" y la deslegitimación de los derechos indígenas y la defensa del medio ambiente como radicales, irracionales e impulsados por intereses extranjeros. En este sentido, los eslóganes no son solo herramientas de legitimación, sino también parte de la formulación de los problemas en juego. Finalmente, Larsen llama también la atención sobre cómo la vernacularización de los esloganes y sus significados produjo interpretaciones contradictorias entre los indígenas. Así, algunas organizaciones indígenas vieron a las políticas neoliberales como un capítulo más de una larga historia de colonización y resistencia. Otras, sin embargo, evocaron una filosofía neoliberal que enfatizaba la elección individual, la propiedad privada y la libertad de empresa y de asociación con las corporaciones.

Juntos, estos artículos contribuyen, desde la antropología, a entender mejor las múltiples, ambiguas y cambiantes articulaciones entre el Estado y los pueblos indígenas amazónicos en el Perú contemporáneo. Los artículos publicados en este dossier demuestran que los indígenas amazónicos no solo han rechazado la intromisión del Estado, sino que al adoptar y tomar parte en prácticas políticas 
estatales, han participado activamente en procesos de formación del Estado en la Amazonía. Por otro lado, los trabajos aquí publicados sostienen que, tanto en el tiempo como en el espacio, el Estado ha mostrado ser cambiante en sus visiones y políticas sobre los pueblos indígenas. Finalmente, los autores de este dossier muestran que el Estado no ha buscado gobernar la Amazonía solamente a través de su aparato institucional sino también a través de la construcción de categorías y representaciones sobre lo indígena. Todo ello nos obliga a replantear la concepción del Estado como un fenómeno fijo y unificado, y la de sus relaciones con los pueblos indígenas como esencialmente antagónicas.

\section{REFERENCIAS}

Abrams, Philip. (2015). Notas sobre la dificultad de estudiar al estado. En Philip Abrams, Akhil Gupta y Timothy Mitchell, Antropología del estado (pp. 1770). México: Fondo de Cultura Económica.

Bengoa, José. (1995). Los indígenas y el Estado nacional en América Latina. Revista de Antropología 38(2), 151-186.

Brown, Michael y Fernández, Eduardo. (2001). Guerra de sombras: la lucha por la utopia en la Amazonía peruana. Lima: Centro Amazónico de Antropología y Aplicación Práctica.

Clark, A. Kim y Becker, Marc. (2007). Indigenous peoples and state formation in modern Ecuador. En A. Kim Clark y Marc Becker (Eds.), Highland Indians and the state in modern Ecuador (pp. 1-21). Pittsburgh: University of Pittsburgh Press.

Chirif, Alberto y García Hierro, Pedro. (2007). Marcando territorio: progresos y limitaciones de la titulación de territorios indígenas en la Amazonía. Copenhague: Grupo Internacional de Trabajo sobre Asuntos Indígenas.

Clastres, Pierre. (1974). La société contre l'État: recherches d'anthropologie politique. Paris: Les Éditions de Minuit.

Corrigan, Philip y Sayer, Derek. (1985). The great arch: English state formation as cultural revolution. Oxford: Basil Blackwell.

Hill, Johathan D. (1999). Indigenous peoples and the rise of independent nationstates in lowland South America. En Frank Salomon y Stuart B. Schwartz (Eds.), The Cambridge history of the native peoples of the Americas, Volume III South America Part 2 (pp. 704-764). Cambridge: Cambridge University Press.

Marzal, Manuel. (1984). Las reducciones indígenas en la Amazonía del virreinato peruano. Amazonía Peruana 5(10), 7-45.

Mitchell, Timothy. (2015). Sociedad, economía y el efecto del estado. En Philip Abrams, Akhil Gupta y Timothy Mitchell, Antropología del estado (pp. 145187). México: Fondo de Cultura Económica. 
Reeve, Mary-Elizabeth. (1988). Los quichua del Curaray: el proceso de formación de la identidad. Quito: Ediciones Abya-Yala.

Santos Granero, Fernando y Barclay, Frederica. (2002). La frontera domesticada: historia económica y social de Loreto, 1850-2000. Lima: Fondo Editorial de la Pontificia Universidad Católica del Perú.

Taylor, Anne Christine. (1999). The western margins of Amazonia from the early sixteenth to the early nineteenth century. En Frank Salomon y Stuart B. Schwartz (Eds.), The Cambridge history of the native peoples of the Americas, Volume III South America Part 2 (pp. 188-256). Cambridge: Cambridge University Press.

Urban, Greg y Sherzer, Joel. (1991). Introduction: Indians, nation-states, and culture. En Greg Urban y Joel Sherzer (Eds.), Nation-states and Indians in Latin America (pp. 1-18). Austin: The University of Texas Press.

Werlich, David Patrick. (1968). The conquest and settlement of the Peruvian montaña [Tesis doctoral]. Universidad de Minnesota. 